\title{
KINETOCARDIOGRAPHY IN CORONARY ARTERY DISEASE
}

\author{
BY
}

\author{
W. SCHWEIZER, R. V. BERTRAB, AND PH. REIST \\ From the Department of Medicine, University Hospital, Basle, Switzerland
}

Received April 24, 1964

The beating heart produces low frequency movements of the anterior chest wall. If these movements are recorded with an externally fixed pick-up device a kinetocardiogram (KCG) (Eddleman et al., 1953) is obtained. The curve is a displacement record of the absolute movements and differs in this respect from tracings registered with pick-up devices resting directly upon the chest wall, e.g. apex cardiography (Marey, 1885; Luisada and Magri, 1952; Benchimol, Dimond, and Carson, 1961).

The normal KCG is well defined. In 30 of 51 normal men between 16 and 30 years of age KCGs similar in shape, relative size of amplitude, and time intervals were found. Only minor deviations were present in the remaining 21 men (von Bertrab, Reist, and Schweizer, 1963). The normal KCG has the following characteristics (Fig. 1): small outward movement during atrial

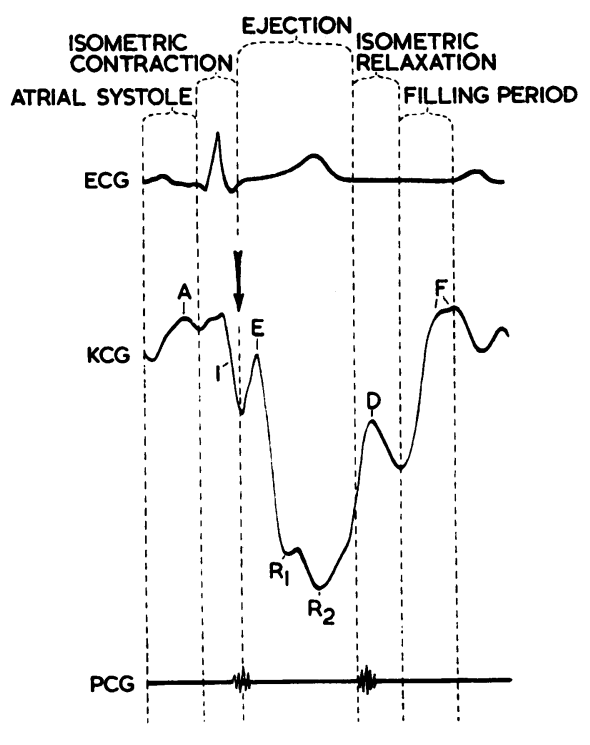

FIG. 1.-The normal kinetocardiogram (see text). Arrow indicates start of the ejection period.

systole (A); minor and variable movements during isometric contraction (I); short outward movement $(E)$ at the beginning of the ejection period, which is dominated by a retraction $(R)$; outward movement in protodiastole (D) and a filling wave (F), beginning at the time of opening of the A-V valves. Small differences only exist between KCGs taken from different regions of the anterior chest wall. Similar curves have been published by authors previously working with this method 
(Eddleman and Harrison, 1963). We did not find, however, a single case of sustained outward movement during the ejection period. The effect of age on the KCG has not yet been investigated. The impossibility of fully excluding coronary artery disease in clinically normal men above the age of 40 years is the major obstacle in investigations of this kind. We know, however, that normal KCGs can be found in normal men up to the age of 70 years (unpublished observations).

In heart disease the KCG is often abnormal. Abnormalities have been found in conditions with altered hæmodynamics (Eddleman, 1959). Abnormal KCGs were obtained also in coronary artery disease (Harrison and Hughes, 1958; Eddleman and Langley, 1962). These latter results are of special interest as the diagnosis of coronary artery disease during the quiescent phase is often unsatisfactory.

This paper describes the result of a kinetocardiographic investigation in 75 patients with coronary artery disease.

\section{Subjects AND Methods}

The 75 patients fall into three groups.

(1) 31 patients with angina on effort (30 men and 1 woman aged 41-69 years) of variable duration (6 weeks to 7 years) without electrocardiographic evidence of cardiac infarction. The heart size was abnormal in 11 out of 30 cases; no radiography was available in one. All had sinus rhythm and none had heart failure. The electrocardiogram was abnormal in 24 cases; in 3 patients left bundle-branch block was present, whereas ST-T segment changes only were found in the others. The blood pressure was greater than $160 / 90 \mathrm{~mm} . \mathrm{Hg}$ in 10 patients.

(2) 19 patients with recent cardiac infarction (16 men and 3 women aged 35-69 years) were investigated 10 to 59 days after the occurrence of the infarction. The electrocardiogram showed signs of anterior wall infarction in 8 and of infarction of the diaphragmatic wall in 7; posterior infarction was found in 1, and in 3 patients the localization of the infarction was not possible. The heart size was abnormal in 9 out of 11 patients; in 8 no radiography was carried out as complete bed-rest had been ordered by the physician in charge. All had sinus rhythm. Heart failure was present in 6 patients at the time of the investigation. Blood pressures higher than $160 / 90 \mathrm{~mm}$. Hg were found in 5 patients.

(3) 25 patients with old cardiac infarction (23 men and 2 women aged 33-70 years) were studied 3 to 60 months after a cardiac infarction had occurred. The exact time of the infarction remained unknown in 6 cases. The electrocardiographic localization of the infarction was the anterior wall in 7, the diaphragmatic wall in 13, and the posterior wall in 2; the necrosis could not be localized in the remaining 3 patients. The heart size was abnormal in 16 and heart failure was found in 8 . All had sinus rhythm. The blood pressure was above $160 / 90 \mathrm{~mm}$. $\mathrm{Hg}$ in 7 patients.

The method used has already been described (von Bertrab et al., 1963). It can be summarized as follows: A capacitive pulse transducer* is fixed at one end of a metal bar. The bar is mounted on an arch above the thorax so that vertical setting of the transducer is possible at every point of the anterior chest wall. The points of recording are indicated in Fig. 2. They are defined by vertical lines used in electrocardiography (first number) and by intercostal spaces (second number). The KCG, standard lead II (ECG), and first and second heart sounds were recorded simultaneously. A carotid pulse tracing, standard lead II, and first and second heart sounds necessary for defining the beginning of the ejection period were taken afterwards. A three-channel direct recording Cardiopan III* was used.

The patients were in the supine position and the tracings were taken in apnœa at the end of a normal expiration.

\section{RESULTS}

The KCG was abnormal in 73 out of 75 cases. In only one case of angina pectoris and in one case of recent cardiac infarction was a normal KCG found. Six out of seven patients with angina on effort and normal ECG at rest had an abnormal KCG.

The following abnormalities were found:

(a) Large A-waves (more than $20 \%$ of the total amplitude) in about 80 per cent of cases (Fig. $3-5)$.

* Philips AG Zürich (Switzerland). 


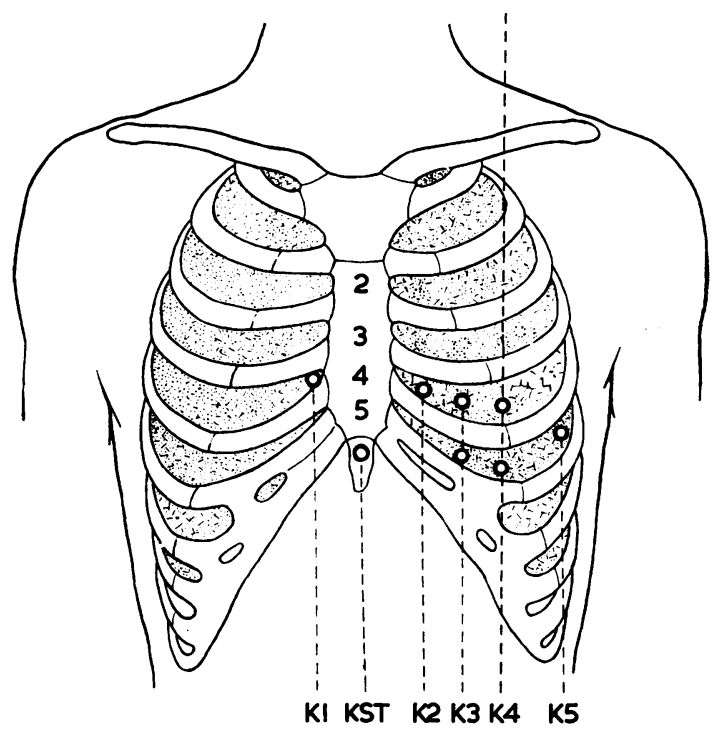

FIG. 2.-The points of recording the kinetocardiogram on the anterior chest wall.

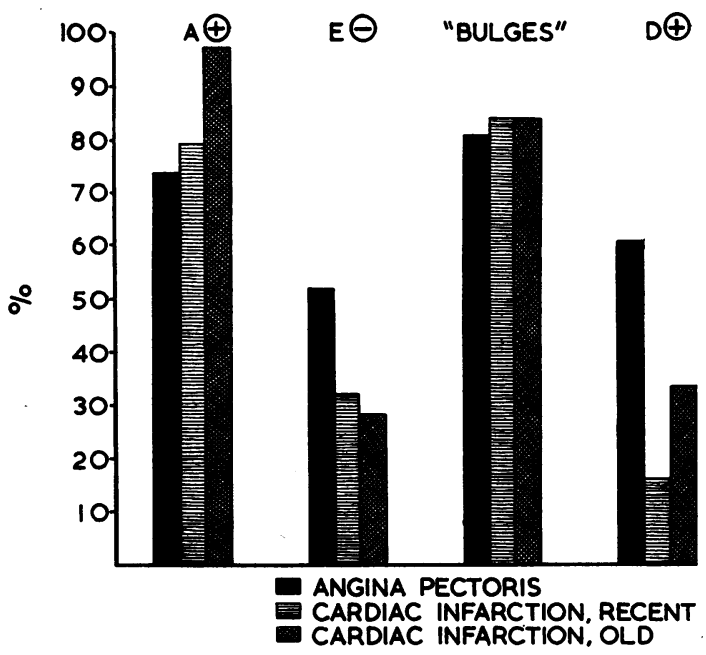

FIG. 3.-The relative frequency of the kinetocardiographic abnormalities found in 75 patients with coronary artery disease. A+, large A waves; $\mathrm{E}-$, small $\mathrm{E}$ waves and small retraction; "Bulges", outward movements during systole; and D+, large $\mathbf{D}$ waves.

(b) Outward movements during systole ("bulges"; Harrison and Hughes, 1958) in approximately 80 per cent of cases (Fig. 3). These "bulges" were seen early in systole beginning during isometric contraction (Fig. 6), in the middle of systole (Fig. 4), or late in systole (Fig. 7). In some cases the bulges were pansystolic (Fig. 8). Mid-systolic bulges were most frequent in angina on

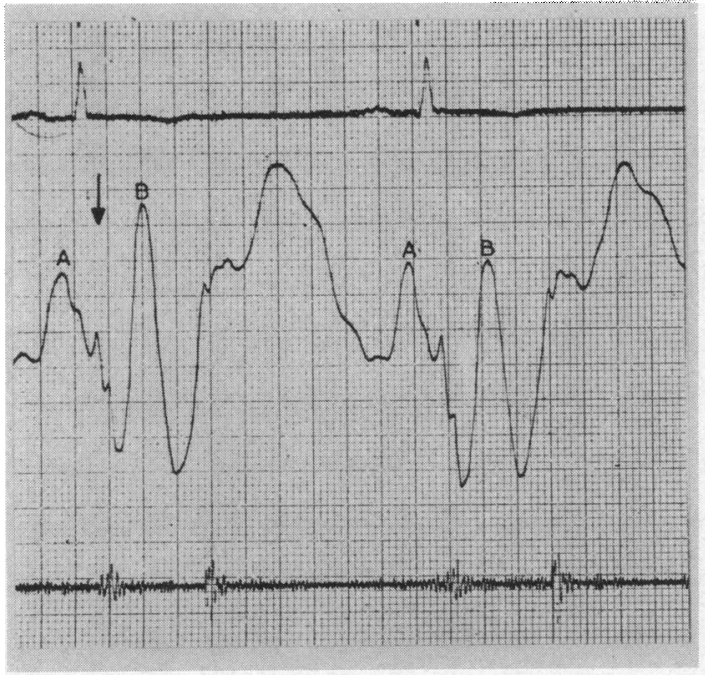

FIG. 4.-KCG (K 4/4) from a man aged 59 years with angina on effort showing large $A$ waves (A) and a mid-systolic "bulge" (B). Negativity of the T wave in lead aVF and standard leads II and III was the only abnormal sign. The blood pressure was $125 / 80 \mathrm{~mm}$. Hg. Arrow, start of the ejection period.

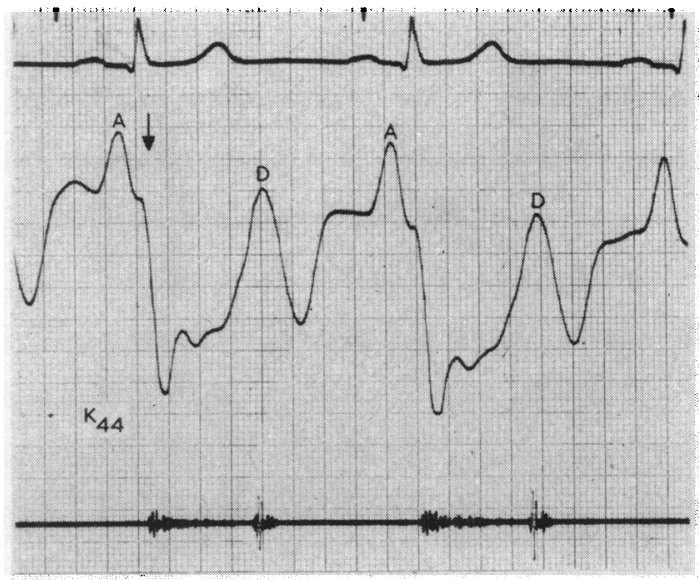

FIG. 5.-KCG taken from a 59-year-old man with angina on effort showing large $A$ waves (A) and large $D$ waves (D). The heart size was within normal limits. A negative T wave in lead aVL, with isoelectric $\mathbf{T}$ in standard lead I was the only electrocardiographic anomaly. The blood pressure was $155 / 80 \mathrm{~mm}$. Hg. Arrow, start of the ejection period. 
TABLE

Relative Frequency of various Abnormal Outward Movements ("Bulges") in 75 Patients with Coronary HeART Disease

\begin{tabular}{l|c|c|c|c}
\hline & \multicolumn{4}{|c}{ "Bulges" (\%) } \\
\cline { 2 - 5 } & Early systolic & Mid-systolic & Late systolic & Pansystolic \\
\hline Angina pectoris (31) & 3 & 61 & 16 & 0 \\
Cardiac infarction (44) & 14 & 34 & 20 & 16 \\
Recent (19) & 10 & 26 & 32 & 16 \\
Old (25) & 16 & 40 & 12 & 16. \\
\hline
\end{tabular}

effort whereas pansystolic bulges were found in cardiac infarction only (Table). Pansystolic bulges were confined to the positions $\mathrm{K} 3 / 4,3 / 5,4 / 4,4 / 5$ whereas the other bulges were frequently present over a larger area.

(c) Small E waves and small retraction in approximately 40 per cent of cases (Fig. 3 and 7).

(d) Large $\mathrm{D}$ waves (more than $50 \%$ of the total amplitude) in 40 per cent of all cases (Fig. 3 and 5).

No definite relation could be established between the different kinetocardiographic abnormalities on the one hand and the heart size, presence of heart failure, electrocardiographic findings, and blood pressure on the other. Although all patients with heart failure and/or arterial hypertension had large A waves, this sign was frequently present in cases without clinically abnormal hæmodynamics. No relation existed between the localization of the various bulges and the site of the infarction judged from the electrocardiogram.

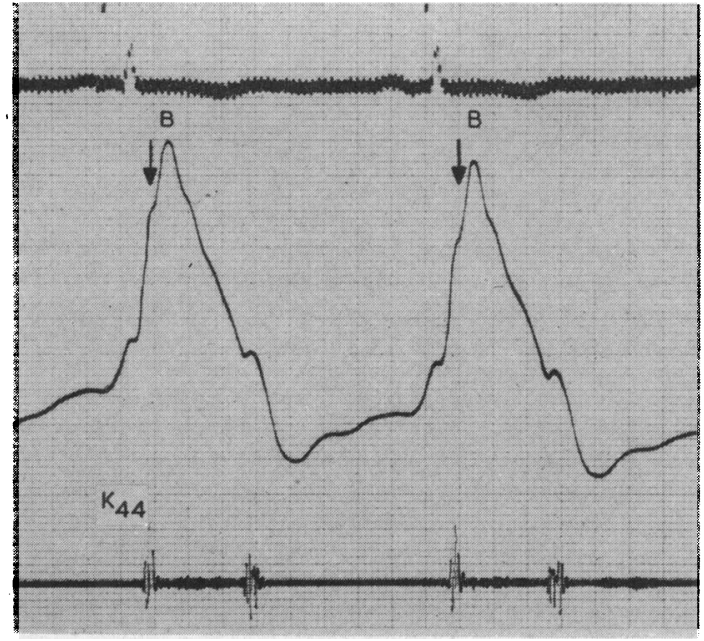

FIG. 6.-KCG from a woman aged 69 with recent cardiac infarction showing an early systolic "bulge" (B). The heart size was abnormal and congestive heart failure was present. The blood pressure had been greater than $200 / 100 \mathrm{~mm}$. $\mathrm{Hg}$ for years; at the time of the investigation it was $180 / 95 \mathrm{~mm}$. Hg. Arrow, start of the ejection period.

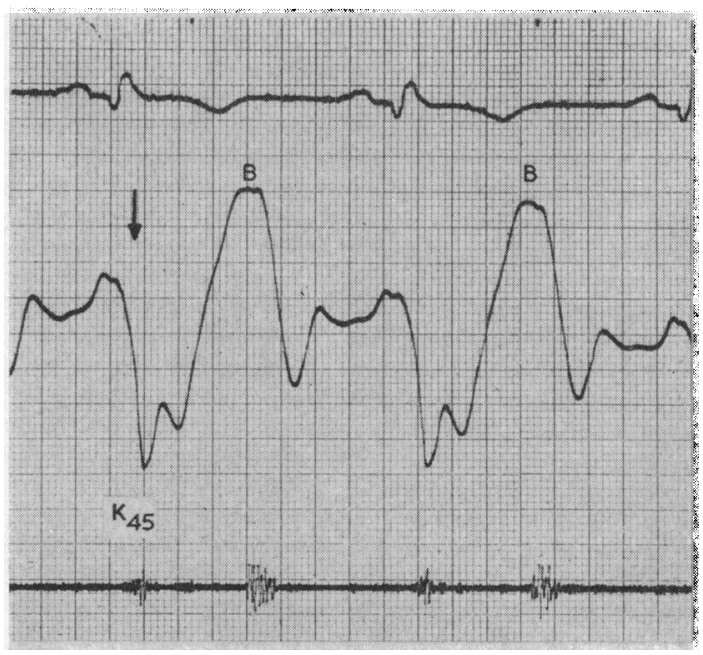

FIG. 7.-KCG taken from a 67-year-old man with recent cardiac infarction, showing a late systolic "bulge" (B). The heart size was normal; a chest radiograph was not recorded. There was no heart failure and the blood pressure was $110 / 75 \mathrm{~mm}$. $\mathrm{Hg}$. Arrow, start of the ejection period. 


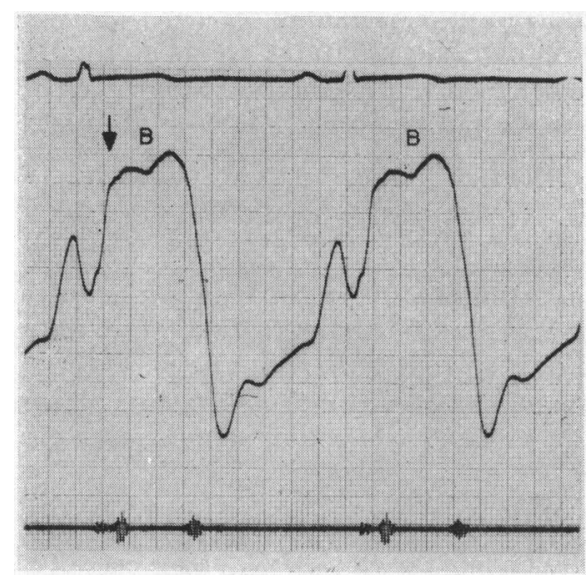

Fig. 8.-KCG K 3/4 from a man aged 47 with recent cardiac infarction showing a pansystolic "bulge"

(B). The heart size was abnormal and a third heart. sound was audible. There was no pulmonary venous congestion or venous hypertension. The blood pressure was $110 / 80 \mathrm{~mm}$. Hg. Arrow, start of the ejection period.

\section{Discussion}

In coronary artery disease two main kinetocardiographic abnormalities are found in the majority of cases: large A waves and outward movements during systole or "bulges". In this respect we have confirmed the observations of the groups of workers who introduced the method of recording (Harrison and Hughes, 1958; Suh and Eddleman, 1959; Skinner et al., 1961a; Davie et al., 1962; Eddleman and Langley, 1962; Eddleman and Harrison, 1963). In our experience, however, the frequency of these abnormalities is even higher than in the investigations mentioned. So we cannot agree with the statement that patients with isolated angina on effort usually have normal KCGs. We found abnormal KCGs in the majority of cases with a normal ECG at rest.

The specificity of these alterations is not yet fully established. It has been shown that large A waves are usually present in congestive heart failure irrespective of the underlying heart disease (Skinner, 1961; Skinner, Nickerson, and Ingram, 1961b). Systolic bulges on the other hand are frequently found in cases with systolic overload of either ventricle. It is highly probable, however, that bulges in the absence of abnormal systolic ventricular pressure and bulges in the $\mathrm{K} 3$ position are signs of coronary artery disease. Furthermore the combination of large $\mathrm{A}$ waves, mid-systolic bulges, and large $\mathrm{D}$ waves seems to be a typical pattern in angina on effort. Little can be said, therefore, about the diagnostic value of kinetocardiography in coronary artery disease.

The pathophysiology of the kinetocardiographic abnormalities found in coronary artery disease is only partially known. Large A waves, as mentioned before, are frequently found in congestive heart failure. They diminish in height or disappear altogether during successful treatment of failure. It is probable therefore that large $\mathbf{A}$ waves are caused by atrial contraction in the presence of an abnormal end-diastolic ventricular pressure. If this is correct one has to assume that in coronary artery disease heart failure is frequent. Müller and Rørvik (1958) have been able to demonstrate a rise of the pulmonary capillary pressure during anginal pain. It is further known that patients with angina on effort are frequently stopped not only by pain but also by breathlessness. An increased resistance to distensibility with abnormal end-diastolic pressure is not excluded however. Tennant and Wiggers (1935) and Prinzmetal et al. (1949) described paradoxical outward movements of the ischæmic myocardial area after the ligation of a large coronary artery branch in dogs ("functional aneurysm"). Kymographic studies, especially electrokymographic investigations have further shown abnormal outward movements of the border of the heart in a considerable proportion of patients with coronary artery disease. (Dack, Sussman, and Master, 1940; Dack, Paley, and Sussman, 1950; Sussman, Dack, and Master, 1940; Luisada and Fleischner, 1948; Samet, Schwedel, and Mednick, 1950.) Finally it is well known that at necropsy anatomical aneurysms are frequently found in these cases (Scherf and Boyd, 1942). It is not known if the bulges are direct evidence of functional or anatomical aneurysm.

It is well known that in patients with coronary artery disease careful palpation of the anterior chest wall sometimes reveals abnormal outward movements. It is said that the frequency of these paradoxical motions is higher in cases of cardiac infarction than in those with angina on effort only, where the abnormality is more often only found during pain (Dressler and Pfeiffer, 1940; Harrison, 1955, 1959; Vakil, 1955; Hurst and Blackard, 1958). The KCG represents the displace- 
ment of the anterior chest wall relative to a fixed external point. As far as outward movements are concerned the KCG shows therefore what can be felt on careful palpation. This close relation between the KCG and the palpatory findings enhances the value of kinetocardiography. The KCG is an objective record: it gives an accurate relation between a given palpatory finding and the cardiac cycle. Finally it reveals more details than palpation, especially the inward movements which are not easily felt.

\section{SUMMARY}

The results of a kinetocardiographic investigation in 75 patients with coronary artery disease are described. The kinetocardiogram was abnormal in 73 cases. An increase of the outward movement during atrial systole and outward movements during ventricular systole were the main abnormalities found. It is probable that systolic outward movements in the absence of abnormal ventricular pressure are specific signs of coronary artery disease. The diagnostic value of the method is not yet known; its establishment is desirable.

\section{REFERENCES}

Benchimol, A., Dimond, E. G., and Carson, J. C. (1961). The value of the apexcardiogram as a reference tracing in phonocardiography. Amer. Heart J., 61, 485.

von Bertrab, R., Reist, Ph., and Schweizer, W. (1963). Das Kinetokardiogramm beim Normalen. Z. Kreisl.Forsch., 52, 553.

Dack, S., Paley, D. H., and Sussman, M. L. (1950). A comparison of electrokymography and roentgenkymography in the study of myocardial infarction. Circulation, 1,551 .

- , Sussman, M. L., and Master, A. M. (1940). The roentgenkymogram in myocardial infarction. II. Clinical and electrocardiographic correlation. Amer. Heart J., 19, 464.

Davie, J. C., Langley, J. O., Dodson, W. H., and Eddleman, E. E. (1962). Clinical and kinetocardiographic studies of paradoxical precordial motion. Amer. Heart J., 63, 775.

Dressler, W., and Pfeiffer, R. (1940). Cardiac aneurysm. A report of ten cases. Ann. intern. Med., 14, 100.

Eddleman, E. E. (1959). The kinetocardiogram-ultra low-frequency precordial movements. In Cardiology, ed. A. A. Luisada, Vol. 2, pp. 3-63 (Supp. 1962). McGraw-Hill, New York.

- and Harrison, T. R. (1963). The kinetocardiogram in patients with ischæmic heart disease. Prog. cardiovasc. Dis., 6, 189.

-, and Langley, J. O. (1962). Paradoxical pulsation of the precordium in myocardial infarction and angina pectoris. Amer. Heart J., 63, 579. - Willis, K., Reeves, T. J., and Harrison, T. R. (1953). The kinetocardiogram. I. Method of recording pre-
cordial movements. Circulation, 8, 269.

Harrison, T. R. (1955). Palpation of the precordial impulses. Stanf. med. Bull., 13, 385.

(1959). Some clinical and physiologic aspects of angina pectoris. Bull. Johns Hopk. Hosp., 104, 275.

, and Hughes, L. (1958). Precordial systolic bulges during anginal attacks. Trans. Ass. Amer. Phycns, $71,174$.

Hurst, J. W., and Blackard, E. (1958). Inspection and palpation of pulsations on the front of the chest. Amer. Heart $J_{.}$, 56, 159.

Luisada, A. A., and Fleischner, F. G. (1948). Tracings of the left ventricle in myocardial infarction. Acta cardiol. (Brux.), 3, 308.

- , and Magri, G. (1952). The low frequency tracings of the precordium and epigastrium in normal subjects and cardiac patients. Amer. Heart J., 44, 545 .

Marey, E. J. (1885). La Méthode Graphique dans les Sciences Expérimentales. Masson, Paris.

Müller, O., and Rørvik, K. (1958). Hæmodynamic consequences of coronary heart disease; with observations during anginal pain and on the effect of nitroglycerine. Brit. Heart J., 20, 302.

Prinzmetal, M., Schwartz, L. L., Corday, E., Spritzler, R., Bergman, H. C., and Kruger, H. E. (1949). Studies on the coronary circulation. VI. Loss of myocardial contractility after coronary artery occlusion. Ann. intern. Med., 31, 429.

Samet, P., Schwedel, J. B., and Mednick, H. (1950). Electrokymographic studies in aneurysm of the left ventricle. Amer. Heart J., 39, 749.

Scherf, D., and Boyd, L. J. (1942). Cardiac aneurysm. Med. Clin. N. Amer., 26, 919.

Skinner, N. S. (1961). Kinetocardiographic findings in patients with congestive heart failure and changes after therapeutic digitalization. Amer. Heart J., 61, 445.

- Leibeskind, R. S., Phillips, H. L., and Harrison, T. R. (1961a). Angina pectoris. Effect of exertion and of nitrites on precordial movements. Amer. Heart J., 61, 250.

- Nickerson, J. F., and Ingram, R. H. (1961b). Kinetocardiographic alterations in patients with congestive heart failure at rest and after exercise. The effect of digitalis. Amer. Heart J., 61, 458.

Suh, S. K., and Eddleman, E. E. (1959). Kinetocardiographic findings of myocardial infarction. Circulation, 19, 531.

Sussman, M. L., Dack, S., and Master, A. M. (1940). The roentgenkymogram in myocardial infarction. I. The abnormalities in left ventricular contraction. Amer. Heart J., 19,453.

Tennant, R., and Wiggers, C. J. (1935). The effect of coronary occlusion on myocardial contraction. Amer. J. Physiol., 112, 351.

Vakil, R. J. (1955). Ventricular aneurysms of the heart. Preliminary report on some new clinical signs. Amer. Heart J., 49, 934. 